\title{
Photocatalytic Degradation of Direct Red 16 Dye using $\mathrm{Ag} / \mathrm{Ag}_{3} \mathrm{VO}_{4} / \mathrm{AgVO}_{3} / \mathrm{GO}$ Nanocomposite
}

\author{
Behzad Hazizadeh Fard ${ }^{\mathrm{a}}$, Roya Ranjineh Khojasteh ${ }^{\mathrm{a}}$ and Parvin Gharbani ${ }^{\mathrm{b}, \star}(\mathbb{D}) \S$ \\ ${ }^{a}$ Department of Inorganic Chemistry, Faculty of Chemistry, Tehran North Branch, Islamic Azad University, Tehran, Iran. \\ ${ }^{b}$ Department of Chemistry, Ahar Branch, Islamic Azad University, Ahar, Iran. \\ Received 3 June 2019, revised 6 August 2019, accepted 20 August 2019.
}

\begin{abstract}
In this research, synthesized $\mathrm{Ag} \mathrm{NPs} / \mathrm{Ag}_{3} \mathrm{VO}_{4} / \mathrm{AgVO}_{3} / \mathrm{GO}$ was applied as a visible-light sensitive photocatalyst for photocatalytic degradation of Direct Red 16 dye (DR16) from aqueous solutions. The synthesized nanocomposite was analyzed by XRD, FESEM, TEM, EDX and Dot mapping. The effect of DR16 dye concentration, $\mathrm{AgNPs} / \mathrm{Ag}_{3} \mathrm{VO}_{4} / \mathrm{AgVO}_{3} / \mathrm{GO}$ dosage, time and pH on photocatalytic removal of DR 16 were studied. Results revealed that $\mathrm{pH}$, dosage and DR16 concentration are more important parameters than time on photocatalytic removal of the dye. The results indicate that $58.98 \%$ of DR16 removal was obtained under the following optimized conditions: DR16 concentration $=32 \mathrm{mg} \mathrm{L}{ }^{-1} ; \mathrm{Ag} \mathrm{NPs} / \mathrm{Ag}_{3} \mathrm{VO}_{4} / \mathrm{AgVO}_{3} / \mathrm{GO}$ dosage $=0.2 \mathrm{~g} 50 \mathrm{~mL}{ }^{-1} ; \mathrm{pH}=4.5 ; 300 \mathrm{~W}$ visible light for $155 \mathrm{~min}$. So, it was concluded that the new nanocomposite can be used as an efficient visible-light photocatalyst for degradation of Direct Red 16 dye.
\end{abstract}

KEYWORDS

$\mathrm{Ag} \mathrm{NPs} / \mathrm{Ag}_{3} \mathrm{VO}_{4} / \mathrm{AgVO}_{3}$, Direct Red 16, graphene oxide, visible light.

\section{Introduction}

The content of wastewaters generated by textile industries are of great concern since these industries employ over 10000 types of dyes, ${ }^{1,2}$ but also include various other organic and inorganic chemicals. ${ }^{3}$ Their high dye content is of major concern as it prevents light penetration through the wastewater receiving resources. ${ }^{4}$ Many of these chemicals cannot be removed by conventional treatment methods, therefore, strict limitations have been considered for their disposal into the environment. ${ }^{5}$ Moreover, biological systems do not degrade many of these pollutants and are toxic to living organisms. ${ }^{6,7}$ The high resistance of the dye molecules is due to the presence of one or more benzene rings, which are toxic and non-degradable and lead to irreversible damage to the environment. Consequently, it is essential to treat the dye wastewaters by appropriate methods before disposing of them into natural water resources. ${ }^{8}$

In particularly, azo dyes should be removed, since they are highly resistant under aerobic conditions and their anaerobic reduction renders aromatic amine by-products, which are intrinsically carcinogenic and mutagenic.,10 One of the most important and widely employed azo dyes is Direct DR16. This dye has been reported to be highly carcinogenic, mutagenic and resistant against biodegradation. ${ }^{11}$ Therefore, an efficient technique should be devised to eliminate DR16 from water and wastewater.

Different physical and chemical processes have been employed to remove dyes, including coagulation and flocculation, chemical oxidation, biological treatment, electrochemical techniques, ion exchange, adsorption, etc. ${ }^{12}$ Among these methods, advanced oxidation processes (AOPs) have been described as efficient techniques for removal of resistant pollutants. ${ }^{13-15}$ Specifically, photocatalytic oxidation processes under UV light in the presence of various catalysts, such as $\mathrm{TiO}_{2}, \mathrm{ZnO}$ and $\mathrm{ZrO}_{2}$

* To whom correspondence should be addressed.

E-mail: parvingharbani@yahoo.com / p-gharabani@iau-ahar.ac.ir have gained more interest in degradation of organic contaminants. ${ }^{16}$ This latter method has been applied to the removal of organic pollutants, particularly azo dyes. ${ }^{17}$ Photocatalytic processes have gained much attention due to their applicability in using solar light as a renewable source of energy and thus in turn, excluding the need for chemicals. ${ }^{18}$ Photocatalysis still has challenges with regard to its general applicability to industrial systems. One of the main challenges is the development of a visible-light-active and highly efficient photocatalyst. ${ }^{19}$ In this respect, application of heterogeneous semiconductor composites has been recommended. ${ }^{20}$ The advantages of these materials are the lack of necessity for high compatibility between the composite components and the possibility of choosing proper bonding agents to provide charge carrier separation and the range of bandgap energies of the various semiconductor materials. ${ }^{21}$

In recent years, interest in composite based on graphene oxide (GO) with silver species has increased since Ag-containing materials present a high photocatalytic efficiency in degradation of organic pollutants under visible-light irradiation. However, Ag species are unstable under this processes and are easily affected by photocorrosion. In fact, under visible-light irradiation, $\mathrm{Ag}^{+}$ reduces to $\mathrm{Ag}^{0}$, the reduced $\mathrm{Ag}$ species block the active photocatalyst sites and therefore decrease their photocatalytic efficiency. ${ }^{22}$ Consequently, the Ag species should be modified to prevent reduction of the Ag ions by the photogenerated electrons. Previous studies have shown that GO is an appropriate material for this purpose as it can capture the photogenerated electrons and prevent the reduction phenomenon. ${ }^{23}$ According to the literature, $\mathrm{Ag}_{2} \mathrm{O}^{24} \mathrm{Ag}_{3} \mathrm{PO}_{4}{ }^{25} \mathrm{Ag}_{2} \mathrm{CO}_{3}{ }^{26}$ and $\mathrm{Ag} / \mathrm{AgX}(\mathrm{X}=\mathrm{Br} \text { or Cl})^{27}$ are more efficient than other $\mathrm{Ag}$ compounds in photocatalytic degradation of organic molecules under visible light. So, modifying the structure of $\mathrm{Ag}$ compounds with GO should improve the visible-light photocatalytic performance.

Response surface methodology (RSM) is a useful technique for evaluation of several input variables that affect the efficiency or the qualitative properties of interest. Also, this method is a bene- 
ficial tool for optimization studies. ${ }^{28}$ RSM proposes a second- or higher-order equation to relate the response to the experimental parameters. The proposed relationship can be used to reach the optimal conditions of the system. ${ }^{29}$ The mathematical relationship between the response and the variables can be expressed as the following second-order polynomial equation:

$$
\mathrm{y}=\beta_{0}+\sum_{\mathrm{i}=1}^{\mathrm{k}} \beta_{\mathrm{i}} \mathrm{x}_{\mathrm{i}}+\sum_{\mathrm{i}=1}^{\mathrm{k}} \beta_{\mathrm{ii}} \mathrm{x}_{\mathrm{i}}^{2}+\sum_{\mathrm{i}=1}^{\mathrm{k}} \sum_{\mathrm{i} \neq \mathrm{j}=1}^{\mathrm{k}} \beta_{\mathrm{ij}} \mathrm{x}_{\mathrm{i}} x_{\mathrm{j}}
$$

where $y$ is the predicted removal efficiency, $x_{i}$ and $x_{i}$ are the variables, $\beta_{0}$ is a constant coefficient, and $\beta_{\mathrm{i}}, \beta_{\mathrm{ii}}$ and $\beta_{\mathrm{ij}}$ are the coefficients of the linear, quadratic and mutual effects, respectively.

This aim of this study is to investigate photocatalytic degradation of the DR16 azo dye by $\mathrm{Ag} \mathrm{NPs} / \mathrm{Ag}_{3} \mathrm{VO}_{4} / \mathrm{AgVO}_{3} / \mathrm{GO}$ nanocomposite under visible light and evaluate the effect of $\mathrm{pH}$, DR16 concentration, time and catalyst dosage on DR16 degradation. The performance of the process is predicted and optimized using a second-order equation by RSM.

\section{Materials and Methods}

Graphite, $\mathrm{KMnO}_{4}, \mathrm{H}_{2} \mathrm{SO}_{4}, \mathrm{HCl}, \mathrm{NaOH}, \mathrm{V}_{2} \mathrm{O}_{5}, \mathrm{~K}_{2} \mathrm{CO}_{3}, \mathrm{H}_{2} \mathrm{O}_{2}$, $\mathrm{AgNO}_{3}, \mathrm{NaNO}_{3}$ were purchased from Merck, Germany. Direct Reactive 16 was obtained from Arta Rezine Arasbaran Company, Iran.

\subsection{Preparation of $\mathrm{Ag} \mathrm{NPs} / \mathrm{Ag}_{3} \mathrm{VO}_{4} / \mathrm{AgVO}_{3} / \mathrm{GO}$}

$240 \mathrm{~mL} \mathrm{AgNO}_{3}(0.1 \mathrm{M})$ and $1.2 \mathrm{~g} \mathrm{GO}$ were stirred vigorously for $90 \mathrm{~min}$ to prepare the $\mathrm{AgNO}_{3} / \mathrm{GO}$ suspension. The $\mathrm{AgNO}_{3} / \mathrm{GO}$ suspension was added dropwise to $60 \mathrm{~mL}$ of a fresh $0.1 \mathrm{M} \mathrm{KVO}_{3}$ solution. The resultant solution was stirred for $30 \mathrm{~min}$ to precipitate a yellow solid. Since the $\mathrm{pH}$ of solution reached 7, a dark green precipitate was formed. The obtained solid was stirred for $1 \mathrm{~h}$ and left overnight at room temperature. The precipitated was washed for several times with deionized water and dried in an oven at $45^{\circ} \mathrm{C} .{ }^{30}$

\subsection{Analysis}

The synthesized nanocomposite was characterized by X-ray diffraction (XRD, X'Pert Pro, Panalytical), field emission scanning electron microscopy (FE-SEM, SIGMA VP-500, Zeiss), transmission electron microscopy (TEMs Zeiss-EM10C-100 KV, Germany), dot mapping and energy dispersive $\mathrm{X}$-ray spectroscopy (AZtec Energy Software, Oxford Instruments). DR5000$15 \mathrm{~V}$ (HACH CO, America) UV-Vis spectrophotometer was used to analysis of the dye concentration at any time.

\subsection{Photodegradation Activity}

To investigate the efficiency of the synthesized nanocomposite, Direct Red 16 dye (Fig. 1) was selected as the model dye.

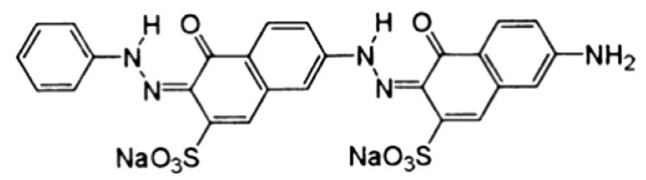

Figure 1 Structure of Direct Red 16 dye.

To perform the photocatalytic degradation experiments, a $300 \mathrm{~W}$ visible light bulb with a tungsten halide filament was used. All experiments were conducted in a batch system at room temperature in a wooden box (Fig. 2). $50 \mathrm{~mL}$ of a DR16 solution of known concentration and desired amount of photocatalyst was transformed to a crystallizer and the $\mathrm{pH}$ of the solution was adjusted using $1 \mathrm{~N} \mathrm{HCl}$ and/or $\mathrm{NaOH}$. The crystallizer was inserted in the wooden light box. To prevent penetration of UV light into the samples, a filter was used. At the desired reaction intervals, the solution was sampled, filtered and the DR16 concentration was measured by a UV-Vis spectrophotometer $\left(\lambda_{\max }=\right.$ $493 \mathrm{~nm})$.

Equation (2) was used to calculate of DR16 removal percentage (\%R).

$$
\mathrm{R}(\%)=\frac{[\mathrm{c}]_{0}-[\mathrm{c}]_{\mathrm{t}}}{[\mathrm{c}]_{0}} \times 100
$$

where, $[\mathrm{C}]_{0}$ and $[\mathrm{C}]_{\mathrm{t}}$ are the initial and at any time concentration of DR16 $\left(\mathrm{mg} \mathrm{L}^{-1}\right)$, respectively.

\subsection{Experiment Design}

Central composite design (CCD) was adopted to develop a proper mathematical model. To evaluate the effect of the operational conditions on photocatalytic removal efficiency, the initial DR16 concentration, $\mathrm{pH}$, time and catalyst dosage were selected as the four independent variables. After performing some preliminary experiments, the five variable levels were chosen (Table 1).

\section{Results and Discussion}

\subsection{Characterization of $\mathrm{Ag} \mathrm{NPs} / \mathrm{Ag}_{3} \mathrm{VO}_{4} / \mathrm{AgVO}_{3} / \mathrm{GO}$}

Crystallized structures of graphene oxide $\left(2 \Theta=11.83^{\circ}\right), \mathrm{Ag}$ cubic phase $\left(2 \Theta=31.35^{\circ}\right)$, mono-clinic $\beta$-AgVO3 phase $(2 \Theta=$

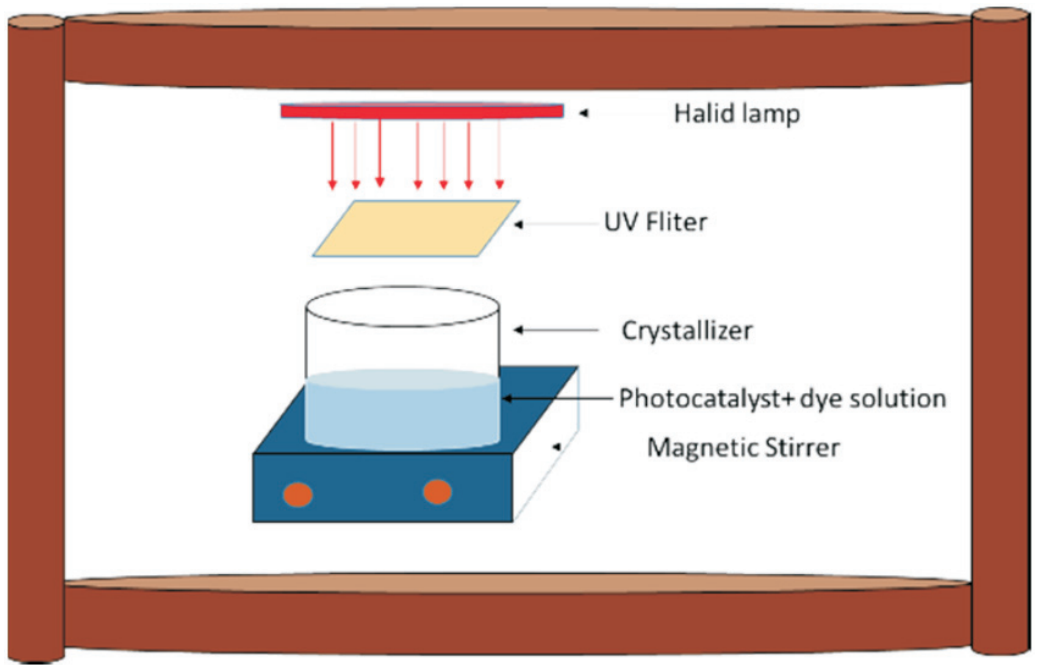

Figure 2 Schematic diagram of photocatalytic system. 
Table 1 The factors and levels of input variables.

\begin{tabular}{|c|c|c|c|c|c|}
\hline Factors & & & Levels & & \\
\hline & $-\alpha$ & -1 & 0 & +1 & $+\alpha$ \\
\hline A : Dosages/g $50 \mathrm{~mL}^{-1}$ & 0.05 & 0.1 & 0.15 & 0.2 & 0.25 \\
\hline B: Dye concentration $/ \mathrm{mg} \mathrm{L}^{-1}$ & 10 & 20 & 30 & 40 & 50 \\
\hline $\mathrm{C}: \mathrm{pH}$ & 2 & 4 & 6 & 8 & 10 \\
\hline D: Time/min & 40 & 80 & 120 & 160 & 200 \\
\hline
\end{tabular}

$33.97^{\circ}$ and $\left.2 \Theta=29.91^{\circ}\right)$ and $\gamma-\mathrm{Ag} 3 \mathrm{VO} 4$ Cubic phase $\left(2 \Theta=38.14^{\circ}\right.$ and $2 \Theta=46.88^{\circ}$ ) is shown in XRD pattern (Fig. 3a). As demonstrated in Fig. 3a, the mono-clinic $\beta-\mathrm{AgVO} 3$ phase $\left(2 \Theta=33.97^{\circ}\right.$ and $2 \Theta=29.91^{\circ}$ ) is the predominant phase in the synthesized nanocomposite. FESEM image (Fig. 3b) shows the morphology of the synthesized photocatalyst. TEM image of nanocomposite shows that Ag nanoparticles are distributed (darker areas) on the leaf-shaped surfaces of GO (Fig. 3c). EDS results (Fig. 3d) confirmed the presence of silver $(22.4 \%)$, vanadium $(2.6 \%)$, carbon $(50.5 \%)$ and oxygen $(24.5 \%)$ in the structure of photocatalyst. Dot mapping image (Fig. 3e) of the nanocomposite also confirms the presence of $\mathrm{Ag}, \mathrm{O}, \mathrm{C}$ and $\mathrm{V}$ elements.

\subsection{Photocatalytic Degradation using RSM}

The experiments were performed by considering the various operational conditions that were suggested by the Design Expert software (DOE 7.0). The experimental (Exp) and predicted (Pre) results of DR16 removal through a 30-run experiment are listed in Table 2.

According to the results of Table 2, the empirical relationship between the response $(R)$ and the independent variables (initial DR16 concentration, catalyst dosage, $\mathrm{pH}$ and time) in photocatalytic degradation of DR16 follows Equation (3):

$\mathrm{R}=+89.79792-18.97500$ * Dosage $+0.92679 *$ Dye Conc. $-35.22437{ }^{*} \mathrm{pH}+0.21774 *$ Time $-3.08750 *$ Dosage * Dye
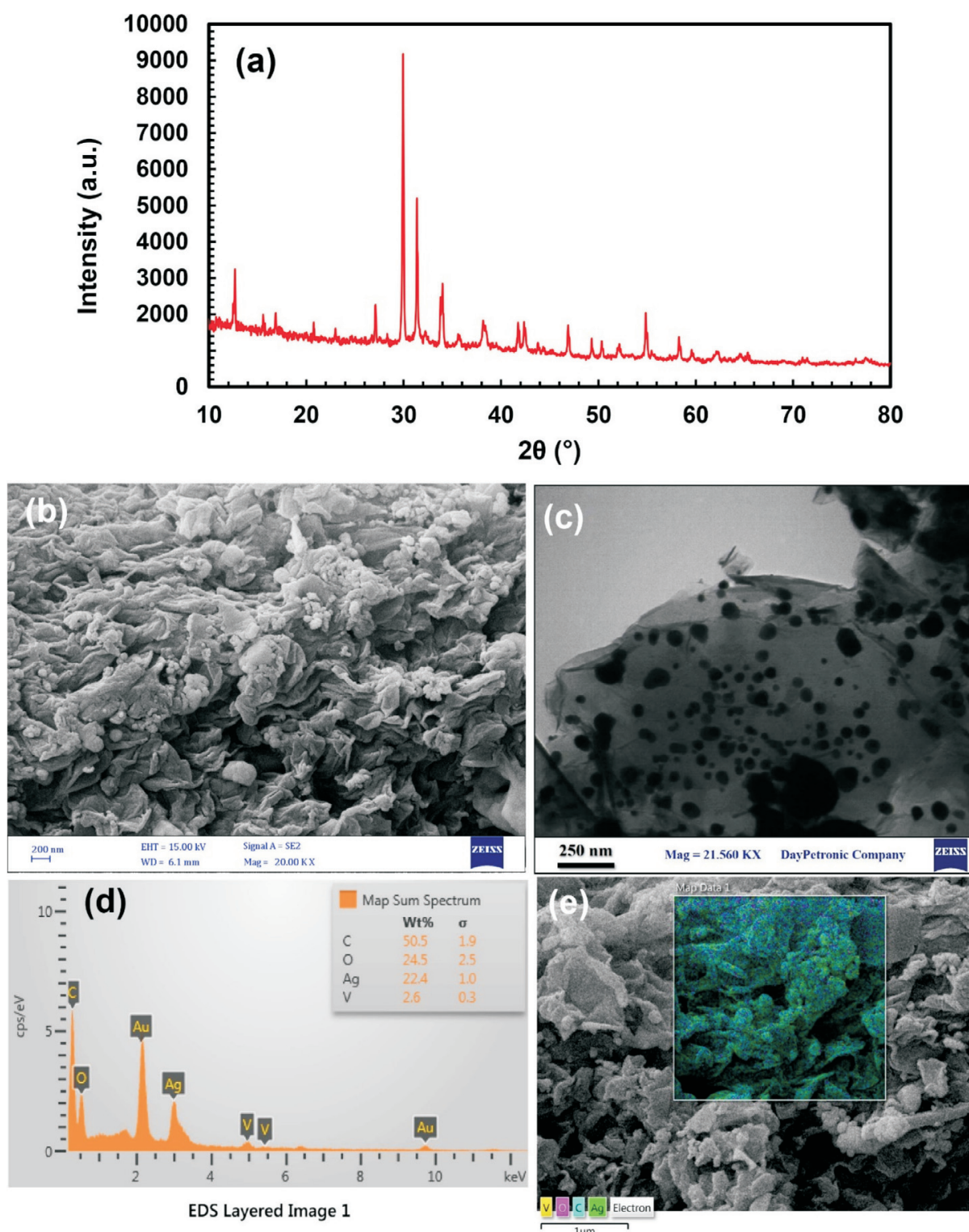

Figure 3 (a) XRD, (b) FESEM, (c) TEM, (d) EDS, (e) Dot mapping results of Ag NPs/ $/ \mathrm{Ag}_{3} \mathrm{VO}_{4} / \mathrm{AgVO}_{3} / \mathrm{GO}$. 
Table 2 Experimental design conditions and experimental (Exp) and predicted (Pre) results.

\begin{tabular}{|c|c|c|c|c|c|c|}
\hline Std & $\begin{array}{l}\text { A: Dosage } \\
\text { /g } 50 \mathrm{~mL}^{-1}\end{array}$ & $\begin{array}{l}\text { B: Dye conc. } \\
\text { /mg L } \mathrm{mg}^{-1}\end{array}$ & $\mathrm{C}: \mathrm{pH}$ & $\begin{array}{l}\text { D: Time } \\
\text { /min }\end{array}$ & $\begin{array}{l}\% \mathrm{R} \\
\text { (Exp) }\end{array}$ & $\begin{array}{l}\% \mathrm{R} \\
\text { (Pre) }\end{array}$ \\
\hline 1 & 0.1 & 20 & 4 & 80 & 22.1 & 22.59 \\
\hline 2 & 0.2 & 20 & 4 & 80 & 26.5 & 26.16 \\
\hline 3 & 0.1 & 40 & 4 & 80 & 24.9 & 24.44 \\
\hline 4 & 0.2 & 40 & 4 & 80 & 21.9 & 21.83 \\
\hline 5 & 0.1 & 20 & 8 & 80 & 14.8 & 14.72 \\
\hline 6 & 0.2 & 20 & 8 & 80 & 31.7 & 31.91 \\
\hline 7 & 0.1 & 40 & 8 & 80 & 16.3 & 16.04 \\
\hline 8 & 0.2 & 40 & 8 & 80 & 28.1 & 27.05 \\
\hline 9 & 0.1 & 20 & 4 & 160 & 17.8 & 18.67 \\
\hline 10 & 0.2 & 20 & 4 & 160 & 19.3 & 19.81 \\
\hline 11 & 0.1 & 40 & 4 & 160 & 35.1 & 35.14 \\
\hline 12 & 0.2 & 40 & 4 & 160 & 30.2 & 30.11 \\
\hline 13 & 0.1 & 20 & 8 & 160 & 9.8 & 10.12 \\
\hline 14 & 0.2 & 20 & 8 & 160 & 24.6 & 24.89 \\
\hline 15 & 0.1 & 40 & 8 & 160 & 25.9 & 26.07 \\
\hline 16 & 0.2 & 40 & 8 & 160 & 34.9 & 34.66 \\
\hline 17 & 0.05 & 30 & 6 & 120 & 13.3 & 12.79 \\
\hline 18 & 0.25 & 30 & 6 & 120 & 24.5 & 24.94 \\
\hline 19 & 0.15 & 10 & 6 & 120 & 5.8 & 4.7 \\
\hline 20 & 0.15 & 50 & 6 & 120 & 15.3 & 16.32 \\
\hline 21 & 0.15 & 30 & 2 & 120 & 61.0 & 60.58 \\
\hline 22 & 0.15 & 30 & 10 & 120 & 56.9 & 57.26 \\
\hline 23 & 0.15 & 30 & 6 & 40 & 5.1 & 5.92 \\
\hline 24 & 0.15 & 30 & 6 & 200 & 10.5 & 9.6 \\
\hline 25 & 0.15 & 30 & 6 & 120 & 18.6 & 18.72 \\
\hline 26 & 0.15 & 30 & 6 & 120 & 18.3 & 18.72 \\
\hline 27 & 0.15 & 30 & 6 & 120 & 19.1 & 18.72 \\
\hline 28 & 0.15 & 30 & 6 & 120 & 19.2 & 18.72 \\
\hline 29 & 0.15 & 30 & 6 & 120 & 18.6 & 18.72 \\
\hline 30 & 0.15 & 30 & 6 & 120 & 18.5 & 18.72 \\
\hline
\end{tabular}

Conc. $+34.06250 *$ Dosage $* \mathrm{pH}-0.30313 *$ Dosage * Time

$-6.56250 \mathrm{E}-003 *{ }^{*}$ Dye Conc. ${ }^{*} \mathrm{pH}+9.14063 \mathrm{E}-003 *$ Dye Conc.

* Time $-2.10937 \mathrm{E}-003 * \mathrm{pH}^{*}$ Time $+14.50000 *$ Dosage $^{2}$

$-0.020513 *$ Dye Conc. $^{2}+2.51250 * \mathrm{pH}^{2}-1.71172 \mathrm{E}-003$ *

Time $^{2}$

where, $\mathrm{R}$ is the DR16 removal \% in photocatalytic process.

Analysis of variance (ANOVA) is one of the most commonly used tools for interpretation of statistical results. Regression analysis was carried out to obtain a second-order polynomial model for prediction of removal efficiency and the obtained data were processed according to the resultant model. Accuracy and (3) validity of the proposed model was assessed by the Design Expert software through ANOVA and regression coefficient $\left(\mathrm{R}^{2}\right)$ analysis. The ANOVA results is presented in Table 3. Variables

Table 3 ANOVA analysis and statistical parameters.

\begin{tabular}{lrrrrr}
\hline Source & Sum of squares & df & Mean square & F-value & P-value Prob $>$ F \\
\hline Model & 2662.42 & 14 & 190.17 & 138.46 & $<0.0001$ \\
\hline A - Dosage & 80.41 & 1 & 80.41 & 58.54 & $<0.0001$ \\
B - Dye conc. & 147.76 & 1 & 147.76 & 107.58 & $<0.0001$ \\
C - pH & 1143.61 & 1 & 1143.61 & 832.61 & $<0.0001$ \\
D - Time & 69.67 & 1 & 69.67 & 50.72 & $<0.0001$ \\
AB & 0.083 & 1 & 0.083 & 0.06 & 0.8095 \\
AC & 5.94 & 1 & 5.94 & 4.33 & 0.0551 \\
AD & 49.18 & 1 & 49.18 & 35.8 & $<0.0001$ \\
BC & 58.71 & 1 & 58.71 & 42.75 & $<0.0001$ \\
BD & 48.83 & 1 & 48.83 & 35.55 & $<0.0001$ \\
CD & 3.85 & 1 & 3.85 & 2.80 & 0.1147 \\
A & 0.021 & 1 & 0.021 & 0.015 & 0.9027 \\
B & 132.42 & 1 & 132.42 & 96.41 & $<0.0001$ \\
C & 801.02 & 1 & 801.02 & 583.19 & $<0.0001$ \\
D $^{2}$ & 0.10 & 1 & 0.10 & 0.076 & 0.787 \\
Residual & 20.60 & 15 & 1.37 & & 0.0597 \\
Lack of fit & 18.47 & 10 & 1.85 & 4.33 & \\
Pure error & 2.13 & 5 & 0.43 & & \\
Cor total & 2683.02 & 29 & & & \\
R $^{2}=0.9923$ & & & & & \\
\hline
\end{tabular}



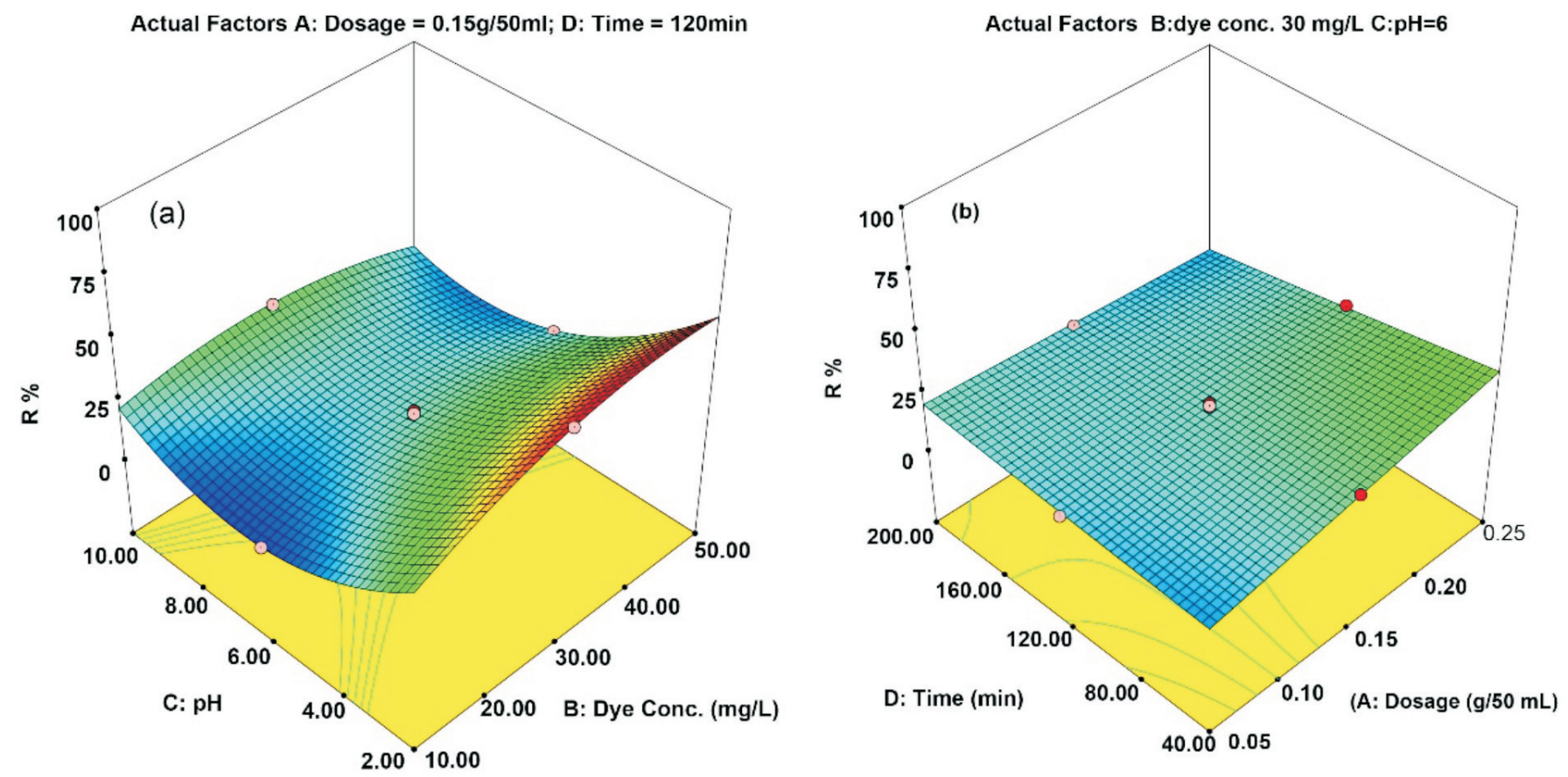

Figure 4 3D response surface plot of interactions; (a) pH and dye concentration; (b) time and dosage in removal of DR16.

are considered as a significant parameter with $\mathrm{P}<0.05$ and large F-value ${ }^{31}$ Based on the results, very low $\mathrm{P}$-values $(\mathrm{P}<0.0001)$ and large F-value (138.46) indicates that the model is highly significant and is well-fitted to the experimental results. Lack of fit (comparison of residual and pure errors) is obtained at about 0.0597 and so is not significant. The $\mathrm{R}^{2}=0.9923$ value confirms the adaptability of the obtained model. As shown in Table 3, dosage, dye concentration, $\mathrm{pH}$, time are highly significant parameters. $\mathrm{AD}, \mathrm{BC}$ and $\mathrm{BD}$ are more significant than $\mathrm{AB}, \mathrm{AC}$ and $C D$ (two factor interaction). $B^{2}$ and $C^{2}$ are more significance than $\mathrm{A}^{2}$ and $\mathrm{D}^{2}$ (quadratic interaction).

To evaluate the interactions between the four operational parameters and response, 3D graphs were plotted (Fig. 4). Figure 4a illustrates the interactions between dye concentration and $\mathrm{pH}$ at constant dosage $=0.15 \mathrm{~g} 50 \mathrm{~mL}^{-1}$ and time $=120 \mathrm{~min}$. As shown, the photocatalytic removal was increased by raising the initial DR16 concentration. It might be attributed to the fact that increasing the DR16 concentration provides a driving force to overcome the resistance against pollutant transport from the solution phase to the surface of the solid. ${ }^{32}$ Also, increasing the $\mathrm{pH}$ reduces the efficiency of the DR16 removal. Since DR16 is an anionic dye, the electrostatic repulsion between this molecule and the negatively charged surface of the composite reduces adsorption of the dye on the surface of the nanocomposite at $\mathrm{pH}>8.4\left(\mathrm{pH}_{\mathrm{zpc}}=8.4\right)$.

Figure $4 \mathrm{~b}$ displays the effect of catalyst dosage and time on the efficiency of DR16 removal at constant dye concentration of $30 \mathrm{mg} \mathrm{L}^{-1}$ and $\mathrm{pH}=6$. As shown, the dye removal was enhanced by incrementing the catalyst dosage. This effect originates from increasing the activated surface and generation of $\mathrm{OH}$ and other oxidative radicals. ${ }^{33}$ In fact, increasing of catalyst dosage leads to the adsorption of more photons and, consequently, degradation of a greater number of DR16 molecules occurs. ${ }^{34-35}$ By considering the effect of time, it can be seen that the change of time had no significant effect on DR16 removal efficiency.

\subsection{Optimal Conditions}

The optimized conditions for removal of DR16 were obtained from the response surface methodology and is presented as:

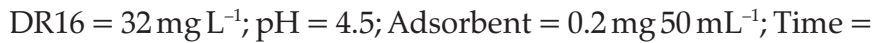
$155 \mathrm{~min}$; Vis. Light $=300 \mathrm{~W}$. Under these conditions, the predicted and experimental removal of DR16 was 61.54 and $58.98 \%$, respectively.

\section{Conclusion}

In this study, $\mathrm{Ag} \mathrm{NPs} / \mathrm{Ag}_{3} \mathrm{VO}_{4} / \mathrm{AgVO}_{3} / \mathrm{GO}$ composite was studied using visible light to photocatalytic remove DR16 from aqueous solutions. Design Expert software was performed to decrease the number of required experiments, saving time and operational cost. According to the obtained results, the most efficient removal of DR16 occurs under acidic solutions. Also, the results indicated that increasing the catalyst dosage and dye concentration improves photocatalytic removal of the dye. Evaluation of the mutual effects of the variables demonstrated that the interaction of the initial DR16 concentration-pH has the most significant effect on the DR16 removal process.

\section{SORCID iD}

\section{P. Gharbani: (iD) orcid.org/0000-0001-9812-3997}

\section{References}

1 P. Gharbani, S M. Tabatabaii and A. Mehrizad, Removal of Congo red from textile wastewater by ozonation, Environ. Sci. Tech., 2008, 5, 495-500.

2 N.P. Tantak and S. Chaudhari, Degradation of azo dyes by sequential Fenton's oxidation and aerobic biological treatment, J. Hazard. Mater., 2006, 136, 698-705.

3 A. Al-kadasi, A. Idris, K. Saed and C.T. Guan, Treatment of textile wastewater by advanced oxidation process, Global Nest, 2004, 6, 222-230.

4 A. Alinsafi, M. Khermis and M.N. Ponsa, Electro-coagulation of reactive textile dyes and textile wastewater, Chem. Eng. Process., 2005, 44, 461-470.

5 S. Hammami, N. Oturan and N. Bellakhal, Oxidative degradation of direct orange 61 by electro-Fenton process using a carbon felt electrode: application of the experimental design methodology, J. Electroanal. Chem., 2007, 610, 75-84.

6 M.R. Hoffmann, S.T. Martin, W. Choi and D.W. Bahnemann, Environmental applications of semiconductor photocatalysis, Chem. Rev. 1995, 95, 69-96.

7 M.A. Oturan, I. Sires and S. Perocheau, Sonoelectro-Fenton process: a 
novel hybrid technique for the destruction of organic pollutants in water, J. Electroanal. Chem., 2008, 624, 322-329.

8 A. Ventura, G. Jacquet, A. Bermond and V. Camel, Electrochemical generation of the Fenton's reagent: application to atrazine degradation, Water Res., 2002, 36, 3517-3522.

9 M.M. Tauber, G.M. Gubitz and A. Rehorek, Degradation of azo dyes by oxidative processes - Laccase and ultrasound treatment, Bioresour. Technol., 2008, 99, 4213-4220.

10 G. Zhang, F. Yang and L. Liu, Comparative study of Fe2+/H2O2 and $\mathrm{Fe} 3+/ \mathrm{H} 2 \mathrm{O} 2$ electro-oxidation systems in the degradation of amaranth using anthraquinone/polypyrrole composite film modified graphite cathode, J. Electroanal. Chem., 2009, 632, 154-161.

11 A. Pandey, P. Singh and L. Iyengar, Bacterial decolorization and degradation of azo dyes, Int. Biodeter. Biodegr., 2007, 59, 73-84.

12 C.S. Chiou, C.Y. Chang and J.L. Shie, Decoloration of reactive black 5 in aqueous solution by Electro-Fenton reaction, Environ. Eng. Manag. J., 2006, 16, 243-248.

13 F. Ali, J. Ali Khan, N.S. Shah, M. Sayed and H.M. Khan, Carbamazepine degradation by UV and UV-assisted AOPs: kinetics, mechanism and toxicity investigations, Process Saf., Environ., 2018,117, 307-314.

14 Y.P. Chen, S.Y. Liu, H.Q. Yu, H. Yin and Q.R. Li., Radiation-induced degradation of methyl orange in aqueous solutions, Chemosphere, $2008,72,532-536$.

15 J. Wang, W. Sun, Z. Zhang, Z. Jiang, X. Wang, R. Xu, R. Li and X. Zhang, Preparation of Fe doped mixed crystal $\mathrm{TiO} 2$ catalyst and investigation of its sonocatalytic activity during degradation of azo fuchsine under ultrasonic irradiation, J. Colloid Interf. Sci., 2008, 320, 202-209.

16 P.S. Kamat, R. Huehn and R. Nicolaescu, Semiconductor nanostructures for simultaneous detection and degradation of organic contaminants in water, Photochem. Photobiol. Chem., 2008, 42, 37-57.

17 N. Daneshvar, S. Aber, V. Vatanpour and M.H. Rasoulifard, Electro-Fenton treatment of dye solution containing orange II, Influence of operational parameters, J. Electroanal. Chem., 2008, 615, 165-174.

18 F. Chen, D. Li, B. Luo, M. Chen and W. Shi, Two-dimensional heterojunction photocatalysts constructed by graphite-like C3N4 and Bi2WO6 nanosheets: enhanced photocatalytic activities for water purification, J. Alloy. Comp., 2017, 694, 193-200.

19 V.R. Dhanak, J.B. Claridge, J.R. Darwent and M.J. Rosseinsky, Nano-structured rhodium doped $\mathrm{SrTiO}_{3}$-Visible light activated photocatalyst for water decontamination, Appl. Catal. B: Environ., 2017, 206, 547-555.

20 M. Feilizadeh, G. Mul and M. Vossoughi, E. coli inactivation by visible light irradiation using a $\mathrm{Fe}-\mathrm{Cd} / \mathrm{TiO} 2$ photocatalyst: statistical analysis and optimization of operating parameters, Appl. Catal. B: Environ. 2015, 168-169, 441-447.

21 G. Yao, Y. Tang, Y. Fu, Z. Jiang, X. An, Y. Chen and Y. Liu, Fabrication of high-quality $\mathrm{ZnCdO}$ epilayers and $\mathrm{ZnO} / \mathrm{ZnCdO}$ heterojunction on sapphire substrates by pulsed laser deposition, Appl. Surf. Sci., 2015, 326, $271-275$
22 Y. Bi, S. Ouyang, J. Cao and J. Ye, Facile synthesis of rhombic dodecahedral $\mathrm{AgX} / \mathrm{Ag}_{3} \mathrm{PO}_{4}(\mathrm{X}=\mathrm{Cl}, \mathrm{Br}$, I) heterocrystals with enhanced photocatalytic properties and stabilities, Phys. Chem. Chem. Phys., 2011, 13, 10071-10075.

23 R. Rana, X. Menga and Z. Zhang, Facile preparation of novel graphene oxide-modified $\mathrm{Ag}_{2} \mathrm{O} / \mathrm{Ag}_{3} \mathrm{VO}_{4} / \mathrm{AgVO}_{3}$ composites with high photocatalytic activities under visible light irradiation, Appl. Catal. B: Environ., 2016, 196, 1-15.

24 Z. Ji, X., Shen, J. Yang, Y. Xu, G. Zhu and K. Chen, Graphene oxide modified Ag2O nanocomposites with enhanced photocatalytic activity under visible-light irradiation, Eur. J. Inorg. Chem., 2013, 2013, 6119-6125.

25 Y. Ao, P. Wang, C. Wang, J. Hou and J. Qian, Preparation of graphene oxide-Ag3PO4 composite photocatalyst with high visible light photocatalytic activity, Appl. Surf. Sci., 2013, 27, 265-270.

26 Y. Song, J. Zhu, H. Xu, C. Wang, Y. Xu, H. Ji, K. Wang, Q. Zhang and H. $\mathrm{Li}$, Synthesis, characterization and visible-light photocatalytic performance of $\mathrm{Ag}_{2} \mathrm{CO}_{3}$ modified by graphene-oxide, J. Alloy. Compd., 2014, 592, 258-265.

$27 \mathrm{M}$. Zhu, P. Chen and M. Liu, Ag/AgBr/graphene oxide nanocomposite synthesized via oil/water and water/oil microemulsions: a comparison of sunlight energized plasmonic photocatalytic activity, Langmuir, 2012, 28, 3385-3390.

28 M.A. Bezerra, R.E. Santelli, E.P. Oliveira, L.S. Villar and L.A. Escaleira, Response surface methodology (RSM) as a tool for optimization in analytical chemistry, Talanta, 2008, 76, 965-977.

29 J. Dasgupta, M. Singh, J. Sikder, V. Padarthi, S. Chakraborty and S. Curcio, Response surface-optimized removal of Reactive Red 120 dye from its aqueous solutions using polyethyleneimine enhanced ultrafiltration, Ecotox. Environ. Safe., 2015, 121, 271-278.

30 B. Hazizadeh Fard, R. Ranjineh Khojasteh and P. Gharbani, Preparation and characterization of visible-light sensitive nano $\mathrm{Ag} / \mathrm{Ag} 3 \mathrm{VO} 4 /$ $\mathrm{AgVO} 3$ modified by graphene oxide for photodegradation of reactive Orange 16 dye, J. Inorg. Organomet. Polym. Mater., 2018, 28, 1149-1157.

31 M.H. Kalavathy, I. Regupathi, M.G. Pillai and L.R. Miranda, Modelling, analysis and optimization of adsorption parameters for $\mathrm{H}_{3} \mathrm{PO}_{4}$ activated rubber wood sawdust using response surface methodology (RSM), Colloids Surf. B: Biointerfaces, 2009, 70, 35-45.

32 R. Arrayo, G. Codoba, J. Padilla and V.H. Lara, Influence of manganese ions on the anatase-rutile phase transition of $\mathrm{TiO}^{2}$ prepared by the sol-gel process, Mater. Lett., 2002, 54, 397-402.

33 C. Shifu, Z. Wei, L. Wei and Z. Sujuan, Preparation, characterization and activity evaluation of $\mathrm{p}-\mathrm{n}$ junction photocatalyst $\mathrm{p}-\mathrm{ZnO} / \mathrm{n}-\mathrm{TiO}_{2}$, Appl. Surf. Sci., 2008, 247, 2484.

34 C. Ling, A. Mohamed and S. Bahatia, Photodegradation of methylene blue dye in aqueous stream, Jurnal Teknologi., 2004, 40, 91-103.

35 S. Chakrabarti and B.K. Dutta, Photo catalytic degradation of model textile dyes in wastewater using Zno as semiconductor catalyst, J. Hazard. Mater., 2004, 112, 269-278. 